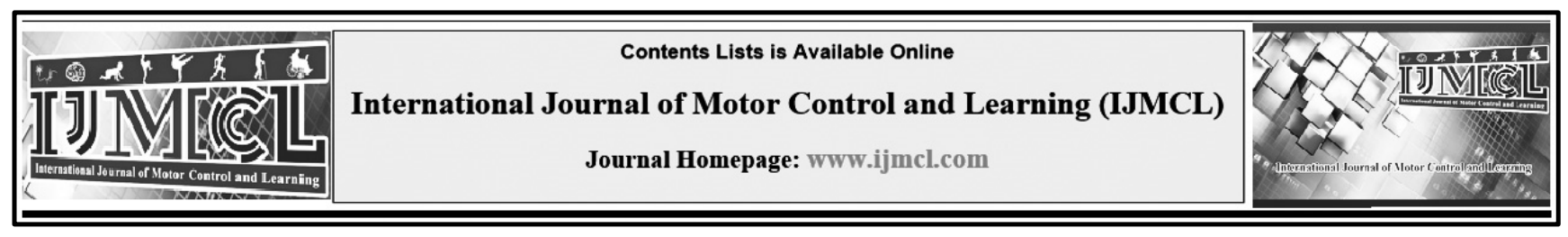

\title{
Distribution of Childhood and Adulthood Attention Deficit/ Hyperactivity Disorder among Iranian Elite Athletes
}

Parisa Rakei ${ }^{\mathrm{a}}$, Mohammad VaezMousavi ${ }^{\mathrm{b}^{*}}$, Zahra Pooraghaei Ardakani ${ }^{\mathrm{c}}$

${ }^{a}$ M.Sc. in Sport Psychology, Department of Sport Science, Allameh Tabataba'I University, Tehran, Iran

${ }^{\mathrm{b}}$ Professor of Sport and Exercise Psychology, Department of Sport Science, Imam Hossein University, Tehran, Iran

${ }^{\mathrm{c}}$ Assistant Professor in Motor Behavior, Department of Sport Science, Allameh Tabataba'I University, Tehran, Iran

\begin{tabular}{|c|c|}
\hline Keywords & Abstract \\
\hline ADHD & Background: Attention Deficit/Hyperactivity Disorder (ADHD) refers to a psychological \\
\hline Clinical Issues & $\begin{array}{l}\text { disorder affecting multiple areas of an individual's life. This disorder is reported to be more } \\
\text { prevalent among athletes in comparison with the general population. }\end{array}$ \\
\hline Elite Athletes & Objective: To the best of our knowledge, there has been no information about the \\
\hline Professional Sports & $\begin{array}{l}\text { distribution of ADHD among Iranian elite athletes. This study was then designed to } \\
\text { investigate the distribution of childhood and adulthood ADHD among Iranian elite athletes. }\end{array}$ \\
\hline Sport Career & $\begin{array}{l}\text { Methods: In this cross-sectional survey, a number of } 180 \text { elite athletes, over } 18 \text { years old, } \\
\text { from various national team camps, were selected through random sampling. The short } \\
\text { version of the Wender-Utah Rating Scale (WURS-K) and Adult Self-Rating Scale (ASRS) }\end{array}$ \\
\hline Mohammad VaezMousavi, & were used for measuring previous childhood and present adulthood ADHD, respectively. \\
\hline Email: mohammadvaezmousavi@chmail.ir & $\begin{array}{l}\text { Results: Findings revealed that approximately a quarter of the Iranian elite athletes used to } \\
\text { suffer from ADHD in their childhood, and } 36 \% \text { of them carried symptoms to their } \\
\text { adulthood life. In addition, } 9.5 \% \text { of the participants only reported the symptoms in their } \\
\text { adulthood. }\end{array}$ \\
\hline Received: 2 & Conclusion: Athletes with different levels of previous Childhood and present Adulthood \\
\hline Accepted: 2021/04/25 & ADHD are able to successfully participate in elite sports. The level of Childhood ADHD \\
\hline Published: 2021/05/15 & can be mostly reduced due to participation in elite sports. \\
\hline
\end{tabular}

\section{Introduction}

ADHD has been reported to influence multiple areas of life dramatically, including education, work, family, and social functioning as a chronic disorder (Nazeer, Mansour, and Gross, 2014). It is the most common childhood psychological disorder which may persist through adolescence and adulthood (Wymbs et al., 2013). Surveys conducted in diverse communities indicate that around $5 \%$ of children and $2.5 \%$ of adults suffer from ADHD (American Psychiatric Association, 2013). Untreated ADHD can exert lifelong detrimental impacts on the individual's development and psychological functions (Nazeer et al., 2014). That is why early diagnosis and treatment, whether behavioral, psychological, or medical, is of great significance to enable children with ADHD to achieve their overall potential capacities (Green and Chee, 1997).

Several researches have investigated the effects of exercise on ADHD symptoms. They concluded that acute and chronic exercise could reduce ADHD symptoms in children (Smith et al., 2013, Gapin \& Etnier, 2014; Gapin, Labban, and Etnier, 2011). In addition, executive functioning of children with ADHD also improved through 
physical exercise (Grassmann, Alves, SantosGalduróz, \& Galduróz, 2016; Hoza, Martin, Pirog, \& Shoulberg, 2016; Ziereis, \& Jansen, 2015; Rommel, Halperin, Mill, Asherson, and Kuntsi, 2013). Moreover, long term physical training with attention-demanding tasks can improve motor performance in these children (Bürgi et al., 2011; Zeng et al., 2017; Pan et al., 2014). Consequently, children with ADHD might be able to moderate inattention, hyperactivity symptoms, behavior, and motor problems due to long term physical activity involvement. Moreover, Song, Lauseng, Lee, Nordstorm, and Katch's (2016) results indicated a positive association between physical activity levels and cognitive and behavioral outcomes in youth whose ADHD was not treated with medications.

Individuals with ADHD tend to engage in athletic activities due to the nature of ADHD symptoms. Indeed, being an athlete is a natural and socially accepted way to manifest and express the hyperactivity and impulsivity symptoms (Smith, 2000). These persons have further involvement in sports in comparison to their peers without ADHD. In other words, for people with ADHD, sports involvement is an appropriate way to satisfy their need for being active as well as improving their quality of life. The sport field is a safe sanctuary for children with ADHD to protect them against negative feedback they receive in other environments (Parr, 2011).

Therefore, competitive sports which take years of chronic physical activity for becoming expert, could probably be advantageous for people with ADHD (White, Harris, and Gibson, 2013).
Impulsivity which can be seen in people with $\mathrm{ADHD}$, is correlated with quick decision making required for a point guard or a baseball catcher (Parr, 2011). In fact, if ADHD can be managed properly, people with this syndrome could potentially become outstanding athletes and dynamic workforces in their communities (Biederman, Petty, Evans, Small, and Faraone, 2010). Consequently, it is not surprising that athletes with ADHD are able to compete in all levels of competitive sports (White et al., 2013; Stewman, Liebman, Fink, and Sandella, 2017).

As statistically shown, $10 \%$ of elite athletes suffer from ADHD in comparison with 4 to $8 \%$ of the general adult population (Strack, Linden, and Wilson, 2011). Michael Phelps, who has won 28 Olympic medals, could be named as the most famous individual with ADHD in the world. In an interview with the Guardian, the British Daily Newspaper, he acknowledged that right after beginning to swim, he realized that the swimming pool was a safe sanctuary for him. He also added that being in the swimming pool relieved his mind (Barkham, 2012). Among those athletes who are aware of their disorder, only a small portion dare to reveal it, because they are concerned about damaging their prestigious career; in sports, no one tends to confess their weakness (Dutton, 2018).

Having considered all the above-mentioned reports and numbers, it needs to be emphasized that there is a lack of systematic study investigating the distribution of ADHD among Iranian athletes. Furthermore, there is a probability that a quite number of elite athletes are unaware of their disorder. They have likely found sports as a factor 
to manage their symptoms and unconsciously feel relieved since they were younger. This investigation increases awareness about this disorder in Iran's professional sports society and opens a path for further research to find appropriate interventions and considerations, in order to support this population through their life and sports career. Taking into account the interviews of some outstanding international athletes on ADHD (Phelps and Abrahamson, 2009; Barkham, 2012), the present study was performed to determine the distribution of childhood and adulthood ADHD among Iranian female and male elite athletes. Consequently, further researches on these ADHD elite athletes may identify patterns and details about the specific barriers they may face; for acquiring knowledge about the condition and supporting their mental health in sports career. In addition, the proportion of childhood to the adulthood ADHD may indicates how a long-term engagement in sport activity may affect ADHD in athletes. The results would be valuable for young ADHD athletes, their parents, coaches and mental health supporters. These results may also help to make these children confident that the sports environment would be a safe place for them to grow and that they have the chance to build their future in this profession.

\section{Method}

\section{Participants}

The accessible population under study included all the Iranian elite athletes in Karate, Skating, Fencing, Kabaddi, Canoeing and Rowing, Taekwondo, Kung Fu, Badminton, Table Tennis, Handball and Basketball who had been invited to the national team camps during last three years. A sample of 180 athletes between 18-33 years of age were selected by random sampling. This sample included 101 males and 79 females. Table 1 shows the number of participants in each sport and separates them by gender and age. In addition, the table shows the mean and standard deviation of participants' age.

Table 1. Description of Participants.

\begin{tabular}{lllllll}
\hline Field & N & Female & Male & Mean Age & S.D age & $\begin{array}{l}\text { Mean Age to Start a } \\
\text { Professional Sport }\end{array}$ \\
\hline Karate & 25 & 16 & 9 & 23.32 & 4.12 & 9.60 \\
Skate & 16 & 7 & 9 & 23.18 & 4.63 & 11.87 \\
Skate Hockey & 18 & 12 & 6 & 26.16 & 2.45 & 12.68 \\
Fencing & 15 & 0 & 15 & 22.93 & 3.63 & 13.14 \\
Kabaddi & 7 & 0 & 7 & 25.57 & 2.57 & 15.42 \\
Canoeing and Rowing & 21 & 13 & 8 & 22 & 3.19 & 13.90 \\
Taekwondo & 12 & 4 & 8 & 21.66 & 3.47 & 10.33 \\
Kung Fu & 15 & 5 & 10 & 24 & 3.33 & 9.25 \\
Badminton & 10 & 4 & 6 & 22.90 & 2.88 & 10.20 \\
Ping-Pong & 6 & 6 & 0 & 25.5 & 4.18 & 11.66 \\
Handball & 6 & 1 & 5 & 26 & 5 & 12.60 \\
Basketball & 29 & 11 & 18 & 22.64 & 4.71 & 12.07 \\
Total & 180 & 79 & 101 & 23.45 & 3.95 & 11.93 \\
\hline
\end{tabular}




\section{Instruments}

\section{- Demographic Questionnaire:}

This researcher-made questionnaire was used to obtain data with a focus on gender, age, education level, the sport they played, the age to start a professional sport, and their positions of playing in the team where applicable.

\section{- Short version of Wender-Utah Rating Scale (WURS-K):}

The original WURS is a self-report questionnaire, consisting of 61 items which is used by adults to retrospectively diagnose the existence of ADHD in their childhood (Ward, Wender, and Reimherr, 1993). The WURS was compiled by which an adult can indicate his childhood's status (6-10 years old) with reference to this disorder (Mccann, Scheele, Ward, and Roy-Byrne, 2000). The shortened form of WURS which was used in the present study was offered by Retz- Junginger et al. (2002). This questionnaire includes 25 questions, including four questions $(4,12,14 \& 25)$ that are lie scales which are not calculated in the test score. Therefore, the total score of the other 21 questions is considered as the test score. The WURS-K has proved to show a high reliability ( $\mathrm{r}=0.9)$ for reuse. The test is in 5point Lickert scale format, ranging from 0 (not at all or very slightly) to 4 (Very much). Consequently, the test score ranges from 0 to 84 (Retz-Junginger et al., 2002). The WURS has been translated to Farsi by Sarrami Foroushani (2001) and its validity coefficient was equal to 0.96 . In the present study, considering the obtained scores, the cutting point was 30 .

\section{- Adult Self- Rating Scale (ASRS-v1.1):}

This scale has been compiled by Adler, Kessler, and Spencer (2003) in association with the World Health Organization. This checklist includes eighteen DSM-IV-TR criteria. The first nine criteria determine attention deficit while the second nine criteria refer to hyperactivity-impulsivity. Each criterion on this checklist signifies the degree of the symptoms related to ADHD during the last six months. The participants are required to determine the degree of their symptoms based on a 5-point Likert scale ranging from zero to four: 0 (never), 1 (rarely), 2 (sometimes), 3 (often), and 4 (very often). As such, the participants' scores range from 0 to 72 on this scale. Internal consistency coefficient of this scale has been reported by international studies to fluctuate between 0.63 and 0.72 (Kessler et al., 2007). Its validity using re-test method (Pearson Correlation) has been also estimated to range between 0.58 and 0.77 (Kessler et al., 2007). The ASRS-v1.1 was translated into Farsi by World Health Organization in 2013. The sensitivity of Farsi version was equal to $70 \%$, the specificity was equal to $99 \%$, and the cutoff point was equal to 50 (Mokhtari, Rabiei, and Salimi, 2015). Shekari, Nahavandi and Ahmadi (2017) reported that the Persian version of ASRS has adequate internal consistency and retained the two structure factors of the original questionnaire. According to Mousavi, Bazrafshan and Khosravi (2020), the internal consistency (Cronbach's alpha $=0.85)$ was satisfying and the sensitivity and specificity of 50\% (95\% CI: 30.3-69.6) and 80.5\% (95\%CI: 70.7-88.3) were reported for the first six questions. In order to achieve the cutting point in 
this scale, by considering the sample of our study, we first add standard deviation (8.37) to the sum of the whole scores (26.83) and after rounding it up, 35 was determined as the cutting point.

\section{Procedure}

The cross-sectional survey was adopted in this research considering the nature of the study and the intended objective. Having selected the sample of the participants, the questionnaires were distributed among the elite athletes participating in our study. The participants answered the questionnaires in the presence of the researcher. This was done to clarify any possible ambiguity in the questionnaire in response to participants' request.

\section{Analysis}

The scores related to both questionnaires were calculated for each participant. The sum of the scores were taken into account consistent with the cutting point for each questionnaire. Those athletes who obtained scores equal to 30 or higher on the childhood questionnaire were diagnosed to have the childhood disorder while those who scored 35 or higher on the adulthood scale were diagnosed to have adulthood disorder. In order to analyze the data, SPSS Version 24 was employed.

\section{Results}

Mean scores for WURS-K was 21.36 (SD=11.07). The lower limit was 0 and the upper limits were 46 and 57 for males and females, respectively. Mean score for ASRS was 26.83 ( $\mathrm{SD}=8.37$ ). The lower limit was 9 and the upper limits for males was 41 and for females was 53.

Table 2. Distribution of Childhood and Adulthood ADHD.

\begin{tabular}{lllll}
\hline & $\begin{array}{l}\text { Total } \\
\text { Distribution }\end{array}$ & $\begin{array}{l}\text { Male } \\
\text { Athletes }\end{array}$ & $\begin{array}{l}\text { Female } \\
\text { Athletes }\end{array}$ & $\begin{array}{l}\text { The Cumulative } \\
\text { Percentage }\end{array}$ \\
\hline Only Childhood ADHD & 29 & 19 & 10 & $16 \%$ \\
Only Adulthood ADHD & 17 & 5 & 12 & $9.5 \%$ \\
Childhood + Adulthood ADHD & 16 & 9 & 7 & $9 \%$ \\
\hline
\end{tabular}

The results showed that 45 participants $(29+$ $16)$, out of 180 , had childhood ADHD (25\%), from which, 16 participants carried the symptom to their adulthood (9\%). A number of 17 participants had only adulthood ADHD (9.5\%). The proportion of ADHD in males and females are not comparable in childhood and adulthood.

\section{Discussion}

The aim of this study was to find the distribution of childhood and adulthood ADHD in Iranian elite athletes. We used two questionnaires for evaluating previous childhood and present adulthood ADHD separately, in adult elite athletes. The findings revealed that, 45 (25\%) athletes scored over cutoff point in the childhood questionnaire; from which 29 athletes (64\%) reported only the childhood symptoms; but the 
others carried the symptoms to their adulthood. Moreover, from participants who reported adulthood ADHD (33 athletes, equal to 18.5\%), 17 athletes $(52 \%)$ showed the symptoms only in their adulthood.

The proportion of childhood ADHD in the general population has been reported around 5\% according to DSM-5 (American Psychiatric Association, 2013), while in the present study, 25\% of the participants reported to have this syndrome in their childhood. As readily apparent, there is a considerable difference between what was found in the present study and the proportion reported by DSM-5 in general population. The fact that the participants of the present study were all elite athletes, may justify this difference. We found an ample amount of evidence indicating the higher involvement of children with ADHD in sport activities to be convinced to attribute the high percentage of childhood ADHD observed in the present study being attributed to the athletic characteristics of the participants. For example, Kaufman, Bajaj and Schiltz (2011) claimed that $71.4 \%$ of boys in a gymnastics team were diagnosed with ADHD. Consequently, Parr (2011) believes, the children with ADHD tend to focus more on sport areas, where they experience success and get positive feedbacks. Nadeau and Quinn (2002) claim hyper-talkative and super social ADHD children, attract more to the sport activities for their social needs as well as to decrease their risk-taking behaviors. Therefore, a number of intrinsic motives (Kilpatrick, Hebert, and Bartholomew, 2005) plus the social opportunities that sport provides (Sirard, Pfeiffer, and Pate,
2006), may suffice for ADHD children to get involved in sport activities. So, these children would probably find sports as the best means to achieve social acceptance while they can prosper their capabilities. In result, ADHD children may involve in sports for a longer period of time, comparing to other children (Parr, 2011).

Attributing these results to the athletic nature of the participants is more acceptable than attributing it to their Iranian nationality, since the childhood ADHD prevalence in Iran is approximately 3.5\%, which is less than 5\% reported in DSM-5 report (Yadegari, Sayehmiri, Zamanian Azodi, Sayehmiri, and Modara, 2018).

Not all participants with childhood ADHD carried the symptom to their adulthood life. Comparing 29 childhood ADHD cases with 16 childhoods plus adulthood ADHD cases, indicates that with the help of long periods of sport activity, they were able to control their symptoms, not to carry them to their adulthood. It worth noting that becoming automatic in skills, which is basic demand for starting an expert path in a sports field, takes a long period of hard training, which may be as long as 10 years according to Fitts and Posner's three stages model of skill acquisition (Fitts, \& Posner, 1967). Participants of the present study started serious sport activities in young age. As mentioned in table 1, the mean of "age to start a professional sport" was under 12 years old (11.93), so, they have been involved in physical activities for a sufficient amount of time to affect their ADHD syndrome. Accordingly, Jensen and Kenny (2004) suggested that children with ADHD need to 
exercise regularly and frequently over a long period, to show large effects on their symptoms.

These participants, as elite athletes were involved in regular, chronic, and intensive exercise programs to be able to efficiently control their symptoms. According to Neudecker, Mewes, Reimers, and Woll (2015), long term exercises are needed for general physical fitness improvement (e.g., running, jumping, coordination tasks, exercise stations, or ball games) and different motor abilities enhancement (e.g., endurance, strength, balance). They also pointed out the benefits of long- term exercises in decreasing the behavioral and emotional dilemmas and improving the accuracy of fine motor abilities in ADHD children. This is in accordance with several other findings (Banaschewski, Besmens, Zieger, and Rothenberger, 2001; Verret, Guey, Berthiaume, Gardiner, \& Beliveau, 2012; Piepmeier et al., 2015; Silva et al., 2015). Plus, the literature indicated the significant beneficial effects of involving in intensive exercise (Piepmeier et al., 2015; Silva et al., 2015). Therefore, the participants in this study who had childhood ADHD, could improve all forms of health indicators including physical, mental, and social well-being by being involved in mixed acute exercise programs, for an extended time. Also, Berger, Muller, Brahler, Philipsen, and Zwaan (2014) showed that the excessive exercising symptoms are significantly higher in adults with only childhood ADHD which supports the idea that ADHD children are more attracted to the field of sports in adulthood. In result, ADHD children have a more tendency for choosing sports as a career (Han et al., 2019), and the sport is an opportunity for them to manage their symptoms and enjoy life. Elite sports, as a beneficial package, could be used as a treatment or a complementary method for helping them to manage the symptoms besides medical and behavioral treatment.

In the present study, 33 participants (18.5\%), had adulthood ADHD, which is in accordance with Stark et al. (2011) who suggested that the prevalence of ADHD in professional athletes was $15-20 \%$. However, this proportion is much higher than $3.4 \%$ which is reported for general population in a cross-national study (Fayyad et al., 2007). Obviously, the proportion of ADHD syndrome observed in professional athletes is much higher than the general population. This was previously mentioned by Nazeer et al. (2014) who found a higher proportion of athletes with ADHD syndrome in both college and professional levels.

Fifty two percent of the athletes with adulthood ADHD did not have the syndrome in their childhood which apparently indicates no relationship between childhood and adulthood ADHD. Moffitt et al. (2015) who carried out a 4decade longitudinal cohort study, emphasized that adulthood ADHD may not necessarily appear after childhood ADHD. In fact people might be diagnosed with ADHD only in adulthood (Caye et al., 2016). Whether or not the prevalence of "only Adulthood ADHD" in this study is being related to the frequent need for impulsivity in professional sport activities is a matter of investigation. This may be supported by the fact that these athletes showed higher scores, especially in impulsivity and hyperactivity symptoms. Adding to this, as Parr (2011) believes, the spontaneous and quick 
decision making, besides hyper focusing on an interesting task, which are related to ADHD; can be advantageous for ADHD athletes in helping them with blocking out distractions during practice or competitions (Hupfeld, Abagis, and Shah, 2018). We need also to keep in mind that the impulsivity and hyperactivity observed in adult athletes may be related to other clinical conditions such as Anxiety, Bipolar, Depression or Dysthymia, Hypomania, or PTSD, which may exist in professional athletes (Schinke, Stambulova, Si, and Moore, 2017; VaezMousavi and Shams, 2017). This may be a matter of investigation in future studies.

Another finding of this study reveals that, prevalence of childhood plus adulthood ADHD among participants of the study was $9 \%$. This finding may have at least two implications: one, people with high scores in childhood ADHD who carry their syndrome to the adulthood may be able to successfully participate in professional sport which may act as a psychosocial treatment for their syndrome. Two, a significant number of ADHD elite athletes need non-pharmacological treatment similar to sporting activities. According to Faraone and Antshel (2008) psychosocial interventions must be the foundation of treatment for people with ADHD.

Also, the vast spread of scores in WURS-K (the scores varied from 30 to 57) implies that ADHD athletes with different level of symptoms are able to participate in professional sport. However, as a limitation, the WURS-k questionnaire cannot precisely assess the severity of ADHD in children. Hence, the accurate severity of the symptoms needs further studies.
Overall, a quarter of the participants reported Childhood ADHD with different severities, and the majority of them (64\%) were able to control their symptoms in the merit of elite sports. As all we discussed, the long-term mixed exercise programs, are the most effective in enhancing general health indicators in children and adolescents with ADHD (Neudecker et al., 2015). Involving in elite sports from childhood, might be a remedy to the ADHD, especially for those with mild range of symptoms (this group average scores in childhood were under 40). The other group carried the symptoms to their adulthood, which shows long term severe exercise has not been able to decrease the ADHD syndromes, indicating a need for medical treatments (Putukian e al., 2011).

\section{Conclusion}

Around a quarter of elite athletes, used to have childhood ADHD syndrome. Of these, 64\% have either controlled or reduced their symptoms by doing professional sports. Athletes with Adult ADHD syndrome can participate at the highest level of competitive sports; meaning that elite sports could be considered as a supplementary treatment for the individuals with ADHD. Childhood ADHD can be mostly controlled due elite sport participation and thus it would be an appropriate future career for ADHD children to pursue.

\section{Limitations}

Using self-report questionnaires is a limitation of the present study. Questionnaires, especially those with retrospective orientation, similar to 
WURS-K, have potential validity threats such as problems in remembering the childhood characteristics vividly. Since the severity of ADHD could not be precisely assessed by questionnaires, this limitation should be taken seriously.

\section{Recommendations}

Considering the limitation of the study, we recommend to use a more detailed method for gathering data, rather than using questionnaire. A qualitative approach, using deep interview about athletes' childhood is recommended. This may shed more light on the history of athletes' past and present ADHD.

\section{References}

1. American Psychiatric Association. (2013). Diagnostic and statistical manual of mental disorders (5th Ed). Washington DC.

2. Banaschewski, T., Besmens, F., Zieger, H., \& Rothenberger, A. (2001). Evaluation of Sensorimotor Training in Children with Adhd. Perceptual and Motor Skills, 92(1), 137-149. Doi: 10.2466/pms.2001.92.1.137.

3. Barkham, P. (2012, August 1). What can athletes with ADHD teach us about the condition? Retrieved from

https://www.theguardian.com/society/2012/aug/01/ athletes-with-adhd.

4. Berger, N. A., Müller, A., Brähler, E., Philipsen, A., \& Zwaan, M. D. (2014). Association of symptoms of attention-deficit/hyperactivity disorder with symptoms of excessive exercising in an adult general population sample. BMC Psychiatry, 14(1). Doi: 10.1186/s12888-014-0250-7.

5. Biederman, J., Petty, C. R., Evans, M., Small, J., \& Faraone, S. V. (2010). How persistent is ADHD? A controlled 10-year follow-up study of boys with ADHD. Psychiatry Research, 177(3), 299-304. Doi: 10.1016/j.psychres.2009.12.010.

6. Bürgi, F., Meyer, U., Granacher, U., Schindler, C., Marques-Vidal, P., Kriemler, S., \& Puder, J. J. (2011). Relationship of physical activity with motor skills, aerobic fitness and body fat in preschool children: A cross-sectional and longitudinal study (Ballabeina). International Journal of Obesity, 35(7), 937-944. doi:10.1038/ijo.2011.54.

7. Caye, A., Spadini, A. V., Karam, R. G., Grevet, E. H., Rovaris, D. L., Bau, C. H. D., ... Kieling, C.
(2016). Predictors of persistence of ADHD into adulthood: a systematic review of the literature and meta-analysis. European Child \& Adolescent Psychiatry, 25(11), 1151-1159. Doi: 10.1007/s00787-016-0831-8.

8. Dutton, J. (2018, January 10). Famous Athletes with ADHD: Inspiring Sports Stars. Retrieved from https://www.additudemag.com/famous-athleteswith-adhd/.

9. Faraone, S. V., \& Antshel, K. M. (2008). Diagnosing and treating attentiondeficit/hyperactivity disorder in adults. World Psychiatry, 7(3), 131-136. Doi: 10.1002/j.20515545.2008.tb00179.x.

10. Fayyad, J., De Graaf, R., Kessler, R., Alonso, J., Angermeyer, M., Demyttenaere, K., . . . Jin, R. (2007). Cross-national prevalence and correlates of adult attention-deficit hyperactivity disorder. British Journal of Psychiatry, 190(5), 402-409. doi:10.1192/bjp.bp.106.034389.

11. Fitts, P.M., \& Posner, M.I. (1967). Human performance. Brooks/Cole.

12. Gapin, J. I., \& Etnier, J. L. (2014). Parental perceptions of the effects of exercise on behavior in children and adolescents with ADHD. Journal of Sport and Health Science, 3(4), 320-325. Doi: 10.1016/j.jshs.2013.03.002.

13. Gapin, J. I., Labban, J. D., \& Etnier, J. L. (2011). The effects of physical activity on attention deficit hyperactivity disorder symptoms: The evidence. Preventive Medicine, 52. Doi: 10.1016/j.ypmed.2011.01.022.

14. Grassmann, V., Alves, M. V., Santos-Galduróz, R. F., \& Galduróz, J. C. F. (2016). Possible Cognitive Benefits of Acute Physical Exercise in Children with ADHD. Journal of Attention Disorders, 21(5), 367371. Doi: $10.1177 / 1087054714526041$.

15. Green, C., Chee, K. (1997) Understanding ADHD A Parent's Guide to Attention Deficit Hyperactivity Disorder in Children. 2nd edition. Vermilion Publishing. ISBN 0009181700.

16. Han, D. H., Mcduff, D., Thompson, D., Hitchcock, M. E., Reardon, C. L., \& Hainline, B. (2019). Attention-deficit/hyperactivity disorder in elite athletes: a narrative review. British Journal of Sports Medicine, 53(12), 741-745. Doi: 10.1136/bjsports2019-100713.

17. Hoza, B., Martin, C. P., Pirog, A., \& Shoulberg, E. K. (2016). Using Physical Activity to Manage ADHD Symptoms: The State of the Evidence. Current Psychiatry Reports, 18(12). Doi:10.1007/s11920-016-0749-3.

18. Hupfeld, K. E., Abagis, T. R., \& Shah, P. (2018). Living "in the zone": hyperfocus in adult ADHD. ADHD Attention Deficit and Hyperactivity Disorders, 11(2), 191-208. Doi: 10.1007/s12402018-0272-y.

19. Jensen, P. S., \& Kenny, D. T. (2004). The effects of yoga on the attention and behavior of boys with Attention-Deficit/hyperactivity Disorder (ADHD). Journal of Attention Disorders, 7(4), 205216. Doi: $10.1177 / 108705470400700403$. 
20. Kaufman, K. R., Bajaj, A., \& Schiltz, J. F. (2011). Attention-deficit/hyperactivity disorder (ADHD) in gymnastics: preliminary findings. Apunts. Medicina De LEsport, 46(170), 89-95. Doi: 10.1016/j.apunts.2011.01.002.

21. Kessler, R. C., Adler, L. A., Gruber, M. J., Sarawate, C. A., Spencer, T., \& Brunt, D. L. V. (2007). Validity of the World Health Organization Adult ADHD Self-Report Scale (ASRS) Screener in a representative sample of health plan members. International Journal of Methods in Psychiatric Research, 16(2), 52-65. Doi: 10.1002/mpr.208.

22. Kilpatrick, M., Hebert, E., \& Bartholomew, J. (2005). College Students Motivation for Physical Activity: Differentiating Men and Women Motives for Sport Participation and Exercise. Journal of American College Health, 54(2), 87-94. Doi: 10.3200/jach.54.2.87-94.

23. Mccann, B. S., Scheele, L., Ward, N., \& Roy-Byrne, P. (2000). Discriminant Validity of the Wender Utah Rating Scale for Attention-Deficit/Hyperactivity Disorder in Adults. The Journal of Neuropsychiatry and Clinical Neurosciences, 12(2), 240-245. Doi: 10.1176/jnp.12.2.240.

24. Moffitt, T. E., Houts, R., Asherson, P., Belsky, D. W., Corcoran, D. L., Hammerle, M., ... Caspi, A. (2015). Is Adult ADHD a Childhood-Onset Neurodevelopmental Disorder? Evidence from a Four-Decade Longitudinal Cohort Study. American Journal of Psychiatry, 172(10), 967-977. Doi: 10.1176/appi.ajp.2015.14101266.

25. Mokhtari, H., Rabiei, M., \& Salimi, S. H. (2015). Adult Attention-Deficit/Hyperactivity Disorder Self-Report Scale--Persian Version. PsycTESTS Dataset. doi:10.1037/t67913-000.

26. Mousavi, A., Bazrafshan, Z., \& Khosrai, A. (2020). Validity and Reliability of Adult ADHD Self-Report Scale Persian Version (ASRS-V1.1-Persian). International Journal of Health Studies. Doi: 10.22100/ijhs.v6i1.718.

27. Nadeau, K. G., \& Quinn, P. O. (2002). Understanding women with $\mathrm{AD} / \mathrm{HD}$. Washington, DC: Advantage Books.

28. Nazeer, A. A., Mansour, M. A., \& Gross, K. A. (2014). ADHD and Adolescent Athletes. Frontiers in Public Health, 2. Doi: 10.3389/fpubh.2014.00046.

29. Neudecker, C., Mewes, N., Reimers, A. K., \& Woll, A. (2015). Exercise Interventions in Children and Adolescents with ADHD: A Systematic Review. Journal of Attention Disorders, 23(4), 307 324. Doi: $10.1177 / 1087054715584053$.

30. Pan, C., Chang, Y., Tsai, C., Chu, C., Cheng, Y., \& Sung, M. (2014). Effects of Physical Activity Intervention on Motor Proficiency and Physical Fitness in Children with ADHD: An Exploratory Study. Journal of Attention Disorders, 21(9), 783795. Doi: $10.1177 / 1087054714533192$.

31. Parr, J. W. (2011). Attention-Deficit Hyperactivity Disorder and the Athlete: New Advances and
Understanding. Clinics in Sports Medicine, 30(3), 591-610. Doi: 10.1016/j.csm.2011.03.007.

32. Phelps, M., \& Abrahamson, A. (2009). No limits: the will to succeed. Free Press. ISBN-10: 9781439157664

33. Piepmeier, A. T., Shih, C.-H., Whedon, M., Williams, L. M., Davis, M. E., Henning, D. A., ... Etnier, J. L. (2015). The effect of acute exercise on cognitive performance in children with and without ADHD. Journal of Sport and Health Science, 4(1), 97-104. Doi:10.1016/j.jshs.2014.11.004.

34. Putukian, M., Kreher, J. B., Coppel, D. B., Glazer, J. L., Mckeag, D. B., \& White, R. D. (2011). Attention Deficit Hyperactivity Disorder and the Athlete: An American Medical Society for Sports Medicine Position Statement. Clinical Journal of Sport Medicine, 21(5), 392-400. Doi: 10.1097/jsm.0b013e3182262eb1.

35. Retz-Junginger, P., Retz, W., Blocher, D., Weijers, H.-G., Trott, G.-E., Wender, P., \& Rössler, M. (2002). Wender Utah Rating Scale (WURS-k) Die deutsche Kurzform zur retrospektiven Erfassung des hyperkinetischen Syndroms bei Erwachsenen. Der Nervenarzt, 73(9), 830-838. Doi: 10.1007/s00115001-1215-X.

36. Rommel, A.-S., Halperin, J. M., Mill, J., Asherson, P., \& Kuntsi, J. (2013). Protection from Genetic Diathesis in Attention-Deficit/Hyperactivity Disorder: Possible Complementary Roles of Exercise. Journal of the American Academy of Child \& Adolescent Psychiatry, 52(9), 900-910. Doi: 10.1016/j.jaac.2013.05.018.

37. Sarrami-Foroushani, P. (1379/ 2001). Validation and reliability of Wender-Utah rating scale to diagnosing the Attention-deficit/Hyperactivity disorder in Isfahan (a city in Iran), unpublished doctorate thesis in Persian, Isfahan University of medical sciences.

38. Schinke, R. J., Stambulova, N. B., Si, G., \& Moore, Z. (2017). International society of sport psychology position stand: Athletes' mental health, performance, and development. International Journal of Sport and Exercise Psychology, 16(6), 622-639. doi:10.1080/1612197x.2017.1295557.

39. Shekari H, Nahavandi A, Ahmadi M. Persian Manuscript of Adult Attention Deficit Hyperactivity Disorder Rating Scale Expected Internal Consistency and Factor Structure in Iranian Medical Students, Ann Mil Health Sci Res. 2017 ; 15(4):e68579. doi:10.5812/amh.68579.

40. Silva, A. P., Prado, S. O., Scardovelli, T. A., Boschi, S. R., Campos, L. C., \& Frère, A. F. (2015). Measurement of the Effect of Physical Exercise on the Concentration of Individuals with ADHD. Plos One, 10(3). doi:10.1371/journal.pone.0122119.

41. Sirard, J., Pfeiffer, K., \& Pate, R. (2006). Motivational factors associated with sports program participation in middle school students. Journal of Adolescent Health, 38(6), 696-703. Doi: 10.1016/j.jadohealth.2005.07.013.

42. Smith, A. L., Hoza, B., Linnea, K., Mcquade, J. D., Tomb, M., Vaughn, A. J., ... Hook, H. (2013). Pilot 
Physical Activity Intervention Reduces Severity of ADHD Symptoms in Young Children. Journal of Attention Disorders, 17(1), 70-82. Doi: 10.1177/1087054711417395.

43. Smith, S. D. (2000). Examining the role of attentiondeficit/hyperactivity disorder (Adhd) in the life experiences of university studentathletes (dissertation).

44. Song, M., Lauseng, D., Lee, S., Nordstrom, M., \& Katch, V. (2016). Enhanced Physical Activity Improves Selected Outcomes in Children With ADHD. Western Journal of Nursing Research, 38(9), 1155-1184. Doi: 10.1177/0193945916649954.

45. Stewman, C. G., Liebman, C., Fink, L., \& Sandella, B. (2017). Attention Deficit Hyperactivity Disorder: Unique Considerations in Athletes. Sports Health: A Multidisciplinary Approach, 10(1), 40-46. doi:10.1177/1941738117742906.

46. Strack, B., Linden, M., \& Wilson, V. S. (2011). Biofeedback \& Neurofeedback applications in sport psychology. Wheat Ridge, CO: Association for Applied Psychophysiology and Biofeedback.

47. VaezMousavi M, Shams A. (2017). Mental Health of Iranian Elite Athletes. Iranian Journal of Health Education and Health Promotion. Doi: 05(03):191202.

48. Verret, C., Guay, M.-C., Berthiaume, C., Gardiner, P., \& Béliveau, L. (2012). A Physical Activity Program Improves Behavior and Cognitive Functions in Children with ADHD: an exploratory study. Journal of Attention Disorders, 16(1), 71-80. Doi: $10.1177 / 1087054710379735$.

49. Ward, M. F., Wender, P. H., \& Reimherr, F. W. (1993). Wender Utah Rating Scale. PsycTESTS Dataset. doi:10.1037/t16514-000.

50. White, R. D., Harris, G. D., \& Gibson, M. E. (2013). Attention Deficit Hyperactivity Disorder and Athletes. Sports Health: A Multidisciplinary Approach, 6(2), 149-156. Doi: $10.1177 / 1941738113484679$.

51. Wymbs, B. T., Molina, B. S. G., Belendiuk, K. A., Pedersen, S. L., Walther, C. A. P., Cheong, J. W., ... Pelham, W. E. (2013). Motorsports Involvement among Adolescents and Young Adults with Childhood ADHD. Journal of Clinical Child \& Adolescent Psychology, 42(2), 220-231. Doi: 10.1080/15374416.2012.759227.

52. Yadegari N, Sayehmiri K, Zamanian Azodi M, Sayehmiri F , Modara F . (2018). the Prevalence of Attention Deficient Hyperactivity Disorder among Iranian Children: A Meta-Analysis, Iran J Psychiatry Behavior Sciences. 12(4):e8990. Doi: 10.5812/ijpbs.8990.

53. Zeng, N., Ayyub, M., Sun, H., Wen, X., Xiang, P., \& Gao, Z. (2017). Effects of Physical Activity on Motor Skills and Cognitive Development in Early Childhood: A Systematic Review. BioMed Research International, 2017, 1-13. doi:10.1155/2017/2760716.

54. Ziereis, S., \& Jansen, P. (2015). Effects of physical activity on executive function and motor performance in children with ADHD. Research in Developmental Disabilities, 38, 181-191. doi:10.1016/j.ridd.2014.12.005. 